González, E. (2014). Un recorrido por tres leyes de fomento a las industrias culturales en Colombia. Revista Lebret (6). Bucaramanga, Colombia: Universidad Santo Tomás, pp. 235-255. ISSN 2145-5996

\title{
Un recorrido por tres leyes de fomento a las industrias culturales en Colombia*
}

\section{Going through the three laws for promoting cultural industries in Colombia}

Estefanía González Vélez

\begin{abstract}
Resumen
El artículo se refiere al impacto que han tenido tres leyes de fomento a las industrias culturales en Colombia, desde una perspectiva cualitativa, que busca comprender la apropiación del sector sobre estas. Presenta un marco conceptual sobre el cambio de paradigma que convierte a la cultura en recurso y capital, sobre las industrias culturales y la legislación, y posteriormente aborda las leyes del libro (Ley 98 de 1993), el cine (Ley 814 de 2003 y 1556 de 2012) y los espectáculos públicos (Ley 1493 de 2011), describiendo algunos de sus elementos más importantes, con el fin de comprender estas herramientas y analizar cómo han incidido en el desarrollo de cada uno de los sectores.
\end{abstract}

Palabras clave

Leyes, industrias culturales, economía creativa.

\section{Códigos de clasificación JEL: Z1}

\begin{abstract}
The article refers the impact the three laws for promoting cultural industries have had in Colombia, from a qualitative perspective, which seeks to understand the sector assimilation over them. It presents a conceptual framework on the paradigm shift that turns culture into a resource and capital, about the cultural industries and legislation, and then it addresses the book (Act 98 of 1993), film (Act 814 of 2003 and 1556 2012) and public performances (Law 1493 of 2011) laws, describing some of its most important elements, in order to understand these tools and analyze how they have influenced the development of each of the sectors.
\end{abstract}

\section{Keywords}

Law, cultural industries, creative economy.

* Resultado del proyecto de investigación: Leyes de fomento para las industrias culturales. Desarrollado con financiación de la Universidad EAN, Colombia.

1 Magíster en Ciencia Política, estudiante del Doctorado en Ciencias Sociales y Humanas, Universidad Nacional de Colombia. Correo electrónico: estefania39@gmail.com 


\section{Introducción}

El presente artículo tiene la intención de dar a conocer algunos de los efectos que han tenido tres leyes de fomento a las industrias culturales en Colombia. Se trata de analizar y describir parte de sus impactos o implicaciones en relación con los subsectores en los que se aplican, a la luz de las necesidades y los retos del presente; de tal suerte que pueda servir a emprendedores y gestores como una herramienta de consulta, y como una propuesta para continuar avanzando en este campo, y generar nuevas investigaciones y conocimiento.

A partir de la Constitución de 1991 y de la Ley 397 de 1997 (Ley General de Cultura), se han creado una serie de mecanismos legales que pretenden fortalecer y desarrollar algunos sectores de la cultura, hoy comprendidos como Industrias Culturales, como son: el libro (sector editorial) y el cine (sector audiovisual); así mismo algunos subsectores como el de los espectáculos públicos (artes escénicas). Cada una de estas leyes ha tenido repercusiones positivas y negativas en el desarrollo de cada sector, especialmente la del libro y la del cine, sancionadas en 1993 y 2003, respectivamente; mientras que la Ley de Espectáculos Públicos, de muy reciente implementación, no alcanza a mostrar grandes impactos.

La Ley del Libro -Ley 98 de 1993- es incluso anterior a la creación del Ministerio de Cultura (Ley 397 de 1997) y busca, a partir de la democratización del libro como principal herramienta para la difusión del conocimiento y la cultura, convertir a Colombia en un gran centro editorial y desarrollar de forma general este sector, mediante la generación de incentivos como la exención de aranceles en la importación de materias primas, tarifas preferenciales para la exportación de libros y la declaración de la Feria del Libro de Bogotá como evento cultural de interés nacional, entre otros. Por su parte, la Ley del Cine -Ley 814 de 2003 - que ha sido modificada por medio de otras leyes, decretos y resoluciones, y complementada de acuerdo con las dinámicas actuales en 2012 mediante la Ley 1556, ha buscado desde el comienzo "propiciar un desarrollo progresivo, armónico y equitativo de la cinematografía nacional y en general promover la actividad cinematográfica en Colombia", por medio de diferentes incentivos como los estímulos, los beneficios tributarios para los inversionistas, acuerdos para la cooperación internacional en la coproducción, la creación del Fondo de Desarrollo Cinematográfico, entre otros. Y, finalmente, la Ley de Espectáculos Públicos - Ley 1493 de 2011, que busca en primera medida formalizar este sector, y a partir de esto, generar mecanismos para su fomento y desarrollo mediante beneficios tributarios, facilitación para la puesta en escena de los espectáculos y apoyo para la generación o mejoramiento de espacios, entre otros.

Analizar los cambios de cada subsector, el proceso de cada una de las industrias a la luz de las diferentes leyes, se constituye un reto investigativo para el desarrollo de las la industrias culturales en el país, que permite comprender la importancia de 
generar políticas y mecanismos de fomento y la manera en que los emprendedores las están apropiando. El análisis de estas leyes permitirá a su vez conocer y comprender modelos de gestión impulsados por estas, como los fondos mixtos y los fondos de desarrollo.

Especialmente, en el caso de la industria cinematográfica, se observa un acelerado crecimiento que se refleja no solo en el aumento del número de las producciones nacionales, sino también en el desarrollo de otros sectores asociados al sector audiovisual como el de la música incidental, los escenarios, y en estrategias como la creación del Fondo Fílmico de Colombia, el Fondo de Desarrollo Cinematográfico, entre otros, lo que contribuye al desarrollo de la industria en el país. A continuación se presenta un recorrido cualitativo por tres leyes mencionadas.

\section{La legislación: herramientas para el fomento de las industrias culturales ${ }^{2}$}

Existe en Colombia, y en general en la mayoría de los países, una normatividad que regula las acciones del Gobierno en sus diferentes niveles (nacional, departamental, municipal), en lo que tiene que ver con la protección del patrimonio cultural, el derecho a la propiedad intelectual, el fomento y estímulo para personas naturales y organizaciones del campo, los derechos de los creadores, artistas y gestores, y el desarrollo de las industrias culturales como la editorial, la cinematográfica y la de artes escénicas, entre otras.

Ahora bien, estas leyes se clasifican de acuerdo con su jerarquía y función. Es así que existen normas constitucionales cuyo objetivo es la "regulación" de la identidad, la diversidad, el patrimonio cultural, la educación, la propiedad intelectual, la participación, información, y acceso a la cultura; por otro lado están las normas legales, que son de alguna manera el desarrollo de las constitucionales; es decir, la manera de "aterrizarlas" para que puedan ser apropiadas por los actores, entre estas, se encuentran la Ley del Libro, Ley de Bibliotecas, Ley del Cine y Ley de Espectáculos Públicos, entre otras. Finalmente, de estas se desprenden las normas administrativas que son los decretos presidenciales, de gobernadores y alcaldes, así como ordenanzas departamentales y acuerdos municipales. A su vez todas las normas anteriores pueden clasificarse como i) restrictivas y de protección o ii) de fomento. Nos interesan en este estudio las segundas, leyes de fomento a las industrias culturales, particularmente la del libro, el cine y la del subsector de los espectáculos públicos, creadas y aprobadas en ese orden.

La Ley del Libro: Ley 98 de 1993, se crea porque Colombia ha buscado democratizar el libro y su uso como medio para la transmisión de conocimiento, fomento a la investigación, difusión de la cultura, conservacion del patrimonio,

2 Cabe aclarar que la primera ley que rige al sector, desde la creación del Ministerio, es la Ley General de Cultura. Disponible en: http://www.bibliotecanacional.gov.co/rnbp/sites/default/files/attach/page/ley_397_de_1997.pdf 
entre otros. Así mismo, ha intentando estimular tanto la producción de todo tipo de libros (literatura, cineficios, escolares, entre otros) como la lectura, y para esto se propuso convertir a Colombia en un gran centro editorial, aumentando la exportación de libros nacionales, la creacion de nuevas librerias, bibliotecas y puestos de venta para libros, revistas, folletos, entre otros. En teoria, la ley busca generar los mecanismos para que esto ocurra, por medio de beneficios tributarios, facilitación de trámites, reduccion en los precios de los materiales; sin embargo, hasta ahora, podemos decir que Colombia está lejos de alcanzar estos objetivos. En los últimos años hemos visto surgir una serie de editoriales independientes que se abren paso en medio de la gran industria internacional, y que funcionan bajo lógicas completamente diferentes; al mismo tiempo hemos visto morir a los grandes de la industria nacional. Paradojicamente, en lugar de aumentar la produccion nacional, las grandes editoriales se han ido acabando, como es el caso de Norma, una editorial de tradicion que cerró recientemente algunas de sus líneas lieterarias. La mayoria del material bibliográfico que se consigue en Colombia sigue llegando desde fuera con altos costos y en realidad a nivel nacional no se cuenta con librerías suficientes para cubrir la demanda de las diferentes ciudades y municipios. Y si bien es cierto que las editoriales independientes están llenando los vacíos de un mercado propio, hay que decir que los precios son poco competitivos: comprar libros en Colombia es bastante costoso. A pocos meses de caducar esta ley, vale la pena revisar cómo ha incidido en el desarrollo del sector, como se la han apropiado las editoriales, de qué manera ha propiciado el consumo y el aumento de los lectores en el país.

La Ley del Cine: Ley 814 de 2003, le ha permitido a Colombia desarrollar un sistema productivo que la ubica hoy como el cuarto país de mayor producción cinematográfica en América Latina después de Argentina, México y Brasil. Este desarrollo involucra inversión extranjera e importantes aportes del sector privado, la generación de múltiples empleos y un importante nivel de transacciones de carácter industrial: cada película nacional genera alrededor de 100 empleos o posiciones de trabajo artístico, autoral y técnico (Conpes, 3462).

El modelo de incentivos de la Ley 814 de 2003 se basa en una contribución parafiscal aplicada a productores de películas nacionales y a distribuidores y exhibidores de películas extranjeras, que recauda cerca de 6 mil millones de pesos por año y que se destina, entre otros, a la producción y divulgación de obras nacionales, formación en aspectos técnicos, creativos y de públicos, instalación de servicios técnicos, ampliación de infraestructura cinematográfica, créditos, garantías financieras, lucha contra la piratería y conservación del patrimonio fílmico (Conpes, 3462).

En gran medida, la Ley del Cine ha tenido que ver con este desarrollo y puede decirse que ha sido la ley mejor apropiada por parte de un sector. No obstante, la industria se ha transformado en los últimos años y esto ha conducido a replantearse ciertos elementos de la ley y su forma de aplicación. En este sentido, en el año 2012 se sanciona la Ley 1556 o nueva Ley del Cine; una ley que proyecta desarrollos muy 
positivos para esta industria a nivel nacional. Así, resulta pertinente de una parte, analizar como la primera ley ha impactado en el desarrollo del sector, y de otra, intentar analizar cómo podría incidir la nueva ley.

Finalmente, la Ley de Espectáculos Públicos: Ley 1493 de 2011, que es la más joven, se crea en principio para formalizar la industria del espectáculo público, de las artes escénicas y se otorgan competencias de control, inspección y vigilancia sobre las sociedades de gestión colectiva. Así mismo, se busca aumentar el acceso y la competitividad, la generación de flujos económicos, la creación de estímulos tributarios, y formas alternativas de financiación.

Ahora bien, como se decía anteriormente la ley es muy reciente, por tanto no se han generado informes o resultados que permitan analizar su impacto; por otro lado, especialemente en las ciudades y municipios más pequeños, donde no hay una política pública cultural consolidada, la ley ha tenido una implementación lenta. Como modelo se encuentra la ciudad de Medellín que se viene consolidando como escenario de grandes espectaculos como los conciertos de Madonna y Beyonce.

\section{La Ley del Libro y el sector editorial}

En la última encuesta de Consumo Cultural (2012), desarrollada por el DANE, se incluyó el Módulo de Hábitos de Lectura, Consumo de Libros y Asistencia a Bibliotecas, con el apoyo de cinco instituciones en el país: el Ministerio de Cultura, el Fondo de las Tecnologías de la Información y las Comunicaciones - Fontic, la Cámara Colombiana del Libro, Fundación para el Fomento de la Lectura - Fundalectura, Centro Regional para el Fomento del Libro en América Latina y el Caribe - Cerlalc. De esta encuesta se concluyó que:

- El mayor porcentaje en la lectura de libros lo presentó la población de 12 a 25 años con $61,3 \%$, mientras que en la lectura de revistas, el mayor porcentaje lo obtuvo la población de 26 a 40 años con el 54,9\%.

- Se destaca que de la población de 12 años y más que sabe leer y escribir y que leyó libros en los últimos doce meses, el promedio es 4 libros por persona, mientras que el promedio de libros leídos para el total de personas de 12 años y más es de 2 libros.

- De las personas que leyeron libros en los últimos doce meses el 67,9\% realizó esta práctica en los últimos tres meses. Respecto a la lectura de periódicos, el $63,2 \%$ del total de la población leyó estas publicaciones en el último mes. El mayor porcentaje de lectura de periódicos en el último mes lo tuvo la población de 26 a 40 años (69,7\%), seguido por las personas de 41 a 64 años $(67,5 \%)$ y la población de 12 a 25 años (55,7\%) (DANE, 2013).

Sin duda, se trata de un panorama muy desalentador. En general, somos un país que no lee. Y en algo tiene que ver la Ley del Libro, de una parte porque está pensada 
casi en su totalidad desde un solo lado de la cadena: desde la producción; pero de otro lado, porque las pocas consideraciones que tiene frente a los consumidores (lectores), como es el hecho por ejemplo de promover los kioskos, tan comunes en el resto del mundo, para la venta de revistas, periódicos, libros y fascículos, entre otros, no ha tenido mayores logros. En general, la ley no propone estrategias para promover el libro entre los consumidores y fortalecer los hábitos de lectura, y no se ocupa para nada de los nuevos medios como herramientas para promover la lectura.

En Colombia no solo es costoso comprar libros, sino también difícil; no obstante, de acuerdo con la Ley de Libro, se debieron generar una serie de acciones que abaratarían los costos de importación y favorecerían la producción nacional, y se promoverían las librerías y bibliotecas. Exceptuando Bogotá y ciudades principales como Medellín o Cali, es difícil encontrar librerías y buenas bibliotecas en el país; y es difícil aun en las grandes ciudades encontrar una oferta amplia y competitiva en precios. Y es que para desarrollar esta o cualquier otra industria es fundamental pensar en los consumidores y estos no parecen ser tan importantes a la hora de legislar; a pesar de que la ley busca "Estimular el hábito de la lectura de los colombianos", no hay acciones concretas, por lo menos planteadas en la misma ley, para alcanzar tal objetivo.

Ahora bien, en cuanto al desarrollo del sector editorial en Colombia, encontramos que este parece estar en detrimento. Al menos eso nos muestran las cifras del último informe de estadísticas del Libro en Colombia de la Cámara Colombiana del Libro ${ }^{3}$, realizado en 2011. En términos de empleo por ejemplo, los empleos generados bajaron de 5599 en 2008 a 4763 en 2011. En cuanto a las exportaciones, estas disminuyeron (en dólares) de 184984885 en 2008, a 102302994 en 2011 y las importaciones, al contrario, aumentaron de 73703252 en 2008 a 76172956 en 2011. La situación aparentemente negativa no se le puede atribuir en su totalidad a la Ley del Libro; sin embargo, si hay que considerar que no se han hecho ajustes con el fin de adaptarse a las nuevas dinámicas del sector editorial y que esta es la única herramienta desde el legislativo que existe para la "democratización y el fomento del libro en Colombia".

Es claro que a nivel mundial existe una crisis de dicho sector, determinada en gran medida por los desarrollos de las nuevas tecnologías; no obstante, esta crisis, a diferencia de lo que suele decirse, no implica la muerte de los libros o el fin de la lectura. Implica si, una transformación que tiene que ver con las formas de producción, pero especialmente con las formas de consumo, y que de no ser comprendida, fácilmente nos conducirá a ese estado. La ley, como ya se ha dicho, es creada en 1993 y la revolución de Internet comienza en esa misma década; no pasarían muchos años para que las grandes editoriales tuvieran que replantearse sus modelos de negocio, y en algunos casos liquidar gran parte de su labor, como es el caso de la Editorial

3 Disponible en: ftp://ftp.camlibro.com.co/Estadisticas/Presentacion\%20Estadisticas\%202011.pdf 
Norma que en 2011 cerró sus líneas de ficción y no ficción, dejando un enorme vacío en la oferta. Es decir, la Ley tiene elementos importantes y útiles para el desarrollo del sector, especialmente en lo que tiene que ver con incentivos como la exención de aranceles en importación de materiales, la exención de impuestos de envío para exportación, entre otros, pero se queda corta frente a los desafíos del presente y las exigencias de los nuevos lectores.

Frente a este panorama desolador, sin embargo, se viene presentando un fenómeno muy positivo, que aunque apenas representa un $2 \%$ de la industria en el país, nos habla de las nuevas posibilidades, del resurgimiento del libro, y sobre todo, nos da una lección sobre cómo abordar las dinámicas y los retos que nos imponen los nuevos medios. Se trata del fenómeno de las editoriales independientes. Algunas de ellas, como: La Silueta, Tragaluz Editores, Rey Naranjo, La Serpiente Emplumada, entre otras, existen desde hace 20 años, otras, las de la nueva generación comenzaron a surgir hace aproximadamente 10 años. Están concentradas principalmente en Bogotá y Medellín; se trata de proyectos personales, liderados por pequeños grupos que decidieron publicar lo que querían leer y como lo querían leer. Son propuestas innovadoras, con una gran riqueza estética y una diversidad en temas y autores que ofrece desde la reedición de grandes autores colombianos, hasta la publicación de novelas gráficas, un género que antes era impensable publicar. Lo que ocurre en parte, según lo explica uno de los fundadores de la librería La Madriguera del Conejo, David Roa, es que "La recesión económica de Europa hizo que casas como Alfaguara y Planeta redujeran su plan editorial y optaran por los proyectos más seguros en términos financieros" (Cromos, 2013)"; así las cosas, se generó un vacío editorial que entraron a llenar las editoriales independientes publicando poesía, novela, novela gráfica, comics, nuevos autores, entre otros, y sobre todo, publicando libros que provoca leer.

Los más antiguos editores independientes se unieron hace algunos años en la Red de Editoriales Independientes Colombiana (REIC), que hoy cuenta con 13 integrantes; los más jóvenes, quienes además le apuestan al libro como objeto, conformaron la Ruta de la Independencia. Ambos grupos han encontrado la posibilidad de desarrollar pequeños proyectos sostenibles, porque si algo los caracteriza a todos es que no quieren ser como los grandes sellos editoriales; le apuntan pequeños tirajes, a libros muy trabajados, a propuestas innovadoras que van más allá del texto. Ambos grupos además, han entendido que la asociatividad, que unir los esfuerzos ofrece grandes posibilidades para su desarrollo. Como colectivo o grupo, le han apostado a posicionarse en la Feria Internacional del Libro de Bogotá, y a participar por Colombia en escenarios internacionales.

Hasta ahora no existen cifras que nos permitan hablar con certeza de los alcances de las editoriales independientes; sin embargo, la mayoría de editores hablan del crecimiento en sus ventas en los últimos años. Rey Naranjo, reportó un incremento del $50 \%$ en la Feria de este año, en comparación con las del año pasado. 
En términos de títulos, pasamos de uno, en el 2010 (la primera vez que participamos en la Feria) a dos o tres, en el año siguiente. En nuestra tercera participación en la Feria, ya ofrecimos 40 y este año llevamos 70 títulos (anota John Naranjo, en entrevista con El Tiempo).

Por su parte, Juan Pablo Fajardo, de La Silueta Ediciones, aseguró que

Nosotros duplicamos las ventas del año pasado a este año, que para nosotros es algo enorme. En número de títulos pasamos de ofrecer 30 el año pasado a tener unos 40 este año, lo que representa un incremento del 33\% (El Tiempo, 2013).

Es decir, estamos frente a un panorama completamente diferente al que se suele pintar sobre el libro en Colombia. ¿Y cómo se explica que en medio de la crisis estas pequeñas empresas editoriales tengan resultado tan exitosos? En gran medida se debe a su modelo de negocio, que busca comprender la realidad, a los diferentes actores que intervienen en la cadena de valor, y por supuesto las lógicas del mercado. Los editores independientes han comprendido muy bien a qué se refiere la cultura de nichos; ellos le apuntan a sectores específicos, conocen su audiencia y saben que ofrecerle. Por ejemplo, Rey Naranjo tiene una gran fortaleza para combinar lo literario con lo gráfico, Icono se destaca en temas históricos y es además reconocido por tener entre sus autores a grandes escritores colombianos, Robot es el experto en comics, mientras que Tragaluz, con un repertorio más variado, se esmera especialmente por hacer libros que son grandes piezas gráficas. De igual manera, las demás editoriales tienen diferentes líneas y le apuntan a nichos especiales; tienen sus propios lectores y autores.

Por otro lado, han sabido aprovechar las nuevas tecnologías para hacer tirajes más pequeños o adaptados a sus necesidades. El libro Memoria por correspondencia de Emma Reyes, editado por Laguna Libros, si bien ha vendido cerca de 6000 copias, empezó con un tiraje de 1000; en muchas ocasiones se empieza incluso con tirajes de 500 ejemplares. Esto hace algunos años era impensable, las máquinas existentes exigían grandes cantidades de impresiones para salvar la inversión, ahora se pueden imprimir unidades sin importar la cantidad, y esto sin duda es un beneficio que permite hacer libros más elaborados y sacar una cantidad que se pueda vender sin tener que terminar en pérdidas. Adicional a esto, utilizan las redes sociales como aliadas para crear comunidades y como herramienta para lanzar los libros, poniendo a disposición de los lectores un capítulo o los primeros apartes de un nuevo proyecto. El libro de los ojos, una propuesta de novela ilustrada de Tragaluz con textos de Ricardo Silva Romero e ilustraciones de Daniel Gómez, fue lanzado al mercado con un booktrailer (http://vimeo.com/63900126).

Pero sin duda, uno de los aprendizajes más importantes y valiosos de las editoriales independientes, es que han entendido que hacen parte de una cadena de valor. Así, establecen relaciones con los autores, con los libreros y con los lectores, gracias a una estrategia coopetition, que permite que un grupo de emprendedores con 
un perfil similar una sinergias para fortalecerse en materia de distribución, consumo y mercadeo, entre otros temas.

Así pues, a las editoriales independientes se suman las librerías independientes; otro extraño caso, que frente a la crisis que enfrentan las librerías más tradicionales y comerciales atendidas por vendedores, nos muestra un panorama optimista de pequeños espacios, atendidos por libreros con reconocida trayectoria, que vienen consolidando un público que recibe positivamente el hecho de poder sentarse a hojear un libro y conversar con alguien que conoce bien lo que le está ofreciendo, y que puede asesorarlo o recomendarle un buen libro. Con las editoriales y las librerías independientes, resurge entonces el librero, una profesión considerada por muchos obsoleta.

Las librerías independientes también tienen un énfasis, tienen una buena selección de libros y una atención personalizada. Les ofrecen a los lectores libros de editoriales poco comerciales que no se consiguen en el mercado masivo. "Estos espacios surgen, de cierta forma, del cansancio de lo que la gente llama peyorativamente 'librería de aeropuerto'; es decir, donde están los best sellers y las obras que, también como en los aeropuertos, hacen un viaje inmediato y desaparecen", comenta el poeta antioqueño Juan Manuel Roca, de la librería Trementina. La mayoría de estos espacios ofrece además tertulias con escritores, editores e ilustradores, talleres, clubes de lectura y cineclubes, además de áreas con Internet inalámbrico para degustar café y realizar eventos culturales y exposiciones de arte. Precisamente, de esta manera logran su subsistencia.

Estamos sin dudas, frente a otras lógicas de consumo que vale la pena entender si queremos fortalecer la industria editorial. Como en las otras industrias culturales (turismo, fonográfica, cinematográfica, de moda, entre otras) las personas no compran objetos, compran experiencias; eso lo han entendido las pequeñas editoriales al hacer libros exclusivos, elaborados, con una riqueza estética y una propuesta innovadora, pero eso no lo ha entendido la ley que sigue pensando en términos de producción: importación de papeles, exportación de libros, compra de imágenes, piezas gráficas y demás.

Ahora bien, frente a la pregunta ¿qué relación tienen las editoriales o las librerías independientes con la Ley del Libro? Las respuestas más generalizadas son "ninguna", "no conocemos bien la ley". No obstante, muchas de ellas tienen excelentes relaciones con el Estado, especialmente con el Ministerio de Cultura y de Educación, para quienes producen contenidos. Entonces, el problema no es que quieren permanecer "independientes" o por fuera del sistema, están interesadas en hacer parte del sector sin convertirse en gran industria, pero no encuentran espacio dentro de la legislación. 


\section{Las leyes del cine}

\section{La Ley del Cine, Ley 814 de 2003: ¿Qué ha pasado en estos 10 años?}

Sin duda los resultados son positivos. A diez años de haberse creado la Ley del Cine, el cine colombiano pasa por un muy buen momento; anteriormente, con grandes dificultades se lograban rodar tres películas por año, pero con la Ley en el 2004 fueron 8 y en el 2012, la cifra llegó a 23 largometrajes. Así mismo, la asistencia a cine de los colombianos ha venido creciendo; de acuerdo con las estadísticas presentadas por Proimágenes Colombia ${ }^{4}$, mientras que durante el primer semestre del 2007 la asistencia fue de 10.9 millones de personas, en el mismo periodo del 2012 fue de 20.2 y en el 2013, alcanza los 22006669 espectadores; es decir, presenta un crecimiento del $8.7 \%$ entre 2012 y 2013 . No obstante, seguimos siendo el segundo país de Iberoamérica con menor asistencia de personas a cine nacional, después de Brasil; en Colombia para el 2012, se estrenaron 23 largometrajes nacionales y el índice de asistencia fue de 0.9 por habitante, frente a México con 67 estrenos en el año y un índice de asistencia de 2 por habitante, o Argentina, con 132 estrenos y un índice de 1.1 por habitante.

Es decir, las cifras para la asistencia a películas nacionales, son menos alentadoras frente al panorama general. En el primer semestre de 2007, la asistencia a películas nacionales fue de 1.4 millones de personas, lo que corresponde al 10,4\% sobre el total de películas proyectadas en Colombia. En 2012, en el mismo periodo, las cifras pasaron a ser 1.6 millones de asistentes, correspondiente al 7.7\% del total, mientras que en 2013 las cifras hablan de 1.4 millones de asistentes, correspondientes al 5.7\%; es decir, la asistencia tiende a disminuir en proporción con el número de estrenos que aumentan.

Uno de los elementos que más ha impulsado la producción audiovisual nacional es la creación de los estímulos tributarios, que permiten que un contribuyente reduzca $\$ 165$ de su renta por cada $\$ 100$ que invierte o done para un proyecto cinematográfico nacional. A su vez, la Ley creó el Fondo de Desarrollo Cinematográfico, que es dirigido por Proimágenes Colombia y que regula los diferentes estímulos para la promoción del cine en el país que provienen de los recursos parafiscales que pagan los productores, exhibidores y distribuidores de cine colombiano; de estos recaudos fueron aprobados en 2013 \$ 19616000000 (10.63 millones de dólares), frente a \$ 4370000 en el 2004, y para un total de \$ 95000000000 entre 2004 y 2012. Estos recursos son asignados a través de convocatorias, estímulos automáticos y otros estímulos. El 70\% de estos recursos son asignados a la creación, producción, coproducción y realización de largometrajes, cortometrajes y documentales; el $30 \%$ restante se destina a líneas de acción complementarias para promover el cine como industria. De acuerdo con el Ministerio de Cultura, en estos diez años, se han

\footnotetext{
4 Todas las cifras presentadas en esta parte del texto han sido tomadas de Proimágenes Colombia.
} 
entregado 79 premios para la producción de largometrajes, 40 de estos entregados a directores con más de una película y 39 a directores para la realización de su ópera prima (Proimágenes, 2014).

De acuerdo con el Ministerio de Cultura, a través del Fondo se han recaudado durante la primera década de la Ley US\$41 millones, que se han invertido en la realización de más de mil proyectos, "desde la escritura de guiones, producción y posproducción, así como para la internacionalización del cine, su preservación y la formación de públicos en el país" (enrodaje.net). De estas producciones, 125 películas y proyectos han participado en escenarios internaciones como festivales, talleres y mercados; en 2012, 30 de estas producciones obtuvieron premios alrededor del mundo.

Así pues, aunque hay cifras positivas en el sector cinematográfico en gran medida gracias a la Ley del Cine, nos falta mucho camino por recorrer. Colombia sigue siendo un país con una escasa audiencia, mucho más para el cine nacional, y más todavía para las películas que pueden ser comprendidas como "mejores producciones" y que reciben más reconocimiento internacional. Entre los años 2007 y el primer semestre de 2013, la única película colombiana que ha estado entre las 5 películas más vistas en el país en un año, fue Paraíso Travel en el 2008, con un total de 931245 espectadores. Ahora, del 4.1 millones de entradas vendidas en el año 2012 para el cine nacional, el 83\% correspondió a cinco películas: La cara oculta, con 649469 espectadores, y que ocupó el puesto número 18 en la posición de ranking general; las siguientes 4 fueron: Mi gente linda, mi gente bella (puesto 20 en el ranking general), El cartel de los sapos (posición 28) Sandresito (posición 41) y Mamá tómate la sopa (posición 50). El 16\% restante corresponde a películas como Chocó, 180 segundos, La Sirga, Apaporis, La Playa DC, muchas de estas premiadas en festivales dentro y fuera del país. En el primer semestre de 2013, la película más vista, superando incluso la número 1 del 2012, es El Paseo con 952825 espectadores (posición 8).

Lo anterior se explica de una parte, bastante obvia, por la escasa formación de públicos, pero también, porque existen grandes dificultades relacionadas con la distribución y exhibición de nuestras películas en el mercado interno así como en el internacional. En Colombia hay 690 pantallas, ubicadas en el 4\% del país, y de estas el 75\% están en Bogotá, Cali, Medellín y Barranquilla y la mitad de ese $75 \%$ está en Bogotá. Lo que implica que la mayor parte de los colombianos no tiene acceso al cine ni general ni nacional; porque adicional al escaso número de pantallas, siempre hay prioridad de las películas internacionales sobre las nacionales. Evidentemente hay un mercado muy pequeño para una industria incipiente.

En síntesis, puede decirse que uno de los mayores aportes de la Ley del Cine (Ley 814 de 2003) es que permitió pensar ese sector como una industria, y esto ha hecho posible el desarrollo de los diferentes eslabones de la cadena productiva, logrando la especialización de los diferentes roles en la realización cinematográfica, y con esto, mejorando los estándares de calidad de nuestras películas. Y si bien es cierto 
que el denominado cine de autor es importante, a la hora de pensar en industria, se hace necesario pensar en temas más globales o transversales a diferentes realidades como lo social, lo político, lo cultural, y eso también ha sido posible gracias a la ley. Sin embargo, estas posibilidades que trae la ley también son un arma de doble filo, pues se proliferan películas, que a juicio de los mejores críticos "no le aportan nada a la formación de públicos con sus terribles cintas, tienen la capacidad de dañar a directores talentosos", así lo afirmó Germán Ossa, en entrevista con el diario El País de Cali. Otros en cambio, como Henry Laguado, consideran que este tipo de películas (no tan buenas artísticamente, pero si muy populares) permiten generar escuela y oportunidades laborales para los trabajadores del sector audiovisual. Podemos decir, entonces, que hay avances importantes en términos técnicos, pero todavía nos queda mucho camino por andar, especialmente en lo que tiene que ver con los contenidos; temas como el narcotráfico y la violencia, siguen siendo muy recurrentes en nuestras películas, mientras que por ejemplo la riqueza literaria del país se sigue dejando de lado.

\section{¿Qué es el Fondo para el Desarrollo Cinematográfico? ${ }^{5}$}

El FDC es un instrumento de financiación que obtiene recursos de los dineros provenientes de la contribución parafiscal, creada mediante la Ley 814 de 2003. Lo que permite este fondo es que los recursos generados por el sector, vuelvan a este para favorecer su crecimiento.

Con los dineros recaudados el Fondo entrega anualmente recursos no reembolsables, para el desarrollo de proyectos cinematográficos nacionales en sus diferentes etapas, desde el desarrollo de guiones hasta la posproducción, distribución y exhibición de las películas. Así mismo, desde el FDC se apoyan actividades de formación afines como técnicos, creativos y realizadores, entre otros, y la formación de públicos con el fin de incentivar la asistencia y el sentido crítico de los contenidos audiovisuales. Del mismo modo, apoya la creación de infraestructura de salas en particular en sitios alejados, la constitución de laboratorios o la lucha contra la piratería, también apoya la conservación del patrimonio audiovisual colombiano.

Ahora bien, la dirección del FDC y las decisiones que este toma, están a cargo del Consejo Nacional de las Artes y la Cultura en Cinematografía - CNACC, conformado por el Ministro de Cultura o su designado, el Director de Cinematografía del Ministerio de Cultura, un representante de los productores de Largometraje, un representante de los distribuidores, un representante de los exhibidores, un representante de los directores, un representante de los Consejos Departamentales o Distritales de Cinematografía o Audiovisuales, un representante del sector artístico creativo y un representante del sector técnico (Proimágenes, 2014).

5 Tomado de: http://www.proimagenescolombia.com/secciones/fdc/que_es_el_fdc.php 
La administración y Secretaría Técnica de este Fondo está a cargo de Proimágenes Colombia según lo estableció la Ley 814, lo que hace con la vigilancia de los órganos de control y fiscalización del Estado (Contraloría, Procuraduría, Contaduría), también con la vigilancia del Ministerio de Cultura, de una auditoría externa seleccionada por el CNACC y de las agremiaciones del cine a través de sus representantes en al CNACC o directamente por ellas.

\section{Lo que puede traer la nueva ley}

Esta ley tiene como objeto el fomento de la actividad cinematográfica de Colombia, promoviendo el territorio nacional como elemento del patrimonio cultural para la filmación de audiovisuales y a través de estos, la actividad turística y la promoción de la imagen del país, así como el desarrollo de nuestra industria cinematográfica (Ley 1556 de 2012).

En julio del 2012, el presidente Juan Manual Santos sancionó la Ley 1556, conocida como "la nueva Ley del Cine", también denominada "la Ley de la Devolución 40/20", con el fin de incentivar a productores internacionales para que vengan a filmar en Colombia y de ofrecerle a los colombianos una oportunidad de demostrar su talento e intercambiar conocimiento.

De acuerdo con la Ley, los productores extranjeros que vengan a rodar a Colombia recibirán un reembolso del $40 \%$ por gastos de servicios cinematográficos y un $20 \%$ en gastos de servicios logísticos. Se entiende por servicios cinematográficos todo lo que tiene que ver con preproducción, producción y posproducción, que sean contratados a través de una o más compañías o personas naturales colombianas, residentes en el país, lo que mejorará el nivel de la producción local; por gastos logísticos, se entiende hotelería, alimentación, trasporte y tiquetes aéreos internacionales. Los productores pueden postular proyectos de cualquier género, largometrajes de más de 70 minutos, cortometrajes de menos de 70 minutos y teleseries con hasta dos episodios; los proyectos institucionales o publicitarios están excluidos. Para aplicar a este beneficio los proyectos deben tener un gasto mínimo de contratados en Colombia?

Según la proyección del Gobierno, esta ley creará alrededor de 4000 empleos, y nuevos negocios por unos 200 millones de dólares. Con ella, Colombia se convierte en el primer país con una ley para fomentar la filmación de películas en su suelo. La noticia sin duda es muy positiva; sin embargo, como con todas las leyes, hay ciertas críticas. "Inicialmente el fondo para las contraprestaciones será de 25 mil millones de pesos que saldrán del presupuesto nacional” (Proimágenes, 2014); es decir, Colombia espera o se prepara para dar respuesta a una inversión extranjera que puede llegar a

6 Recuperado de http://www.cancilleria.gov.co/sites/default/files/tramites_servicios/visas/archivos/ley155609 072012.pdf

7 Según la ley, el gasto debe ser superior a 1800 Salarios Mínimos Mensuales Vigentes calculados en pesos colombianos 
los 42 millones de dólares en su primer año. Las expectativas para el año siguiente (2013) no solo tienen que ver con los recursos para darle sostenibilidad a este fondo, sino también con su reglamentación.

\section{Ley de espectáculos públicos}

Sin la Ley de Espectáculos Paul Mccartney no se hubiera presentado en Colombia, ni Madonna vendría a Medellín. Sin la Ley no se habría creado un impuesto parafiscal que, en el caso específico de Madonna, le dejará a Medellín \$1 600000000 de pesos para ser invertidos en el sector cultural (afirmó Manuel José Álvarez, asesor de Teatro del Ministerio de Cultura, en entrevista con el periódico El Mundo).

Realizar espectáculos públicos en Colombia era casi un imposible; entre los altos costos que debían pagar los empresarios, los impuestos que debían asumir los artistas, y la cantidad absurda de trámites que se debían realizar para hacer o traer un espectáculo de las artes escénicas al país, nos estábamos quedando sin opciones para ver y disfrutar. A raíz de esta situación se generaron polémicas y debates desde los diferentes actores (productores, artistas, público), que terminaron por conducir a la sanción de la Ley 1493 de 2011, Ley de Espectáculos Públicos.

El objetivo de esta ley es tanto formalizar como fortalecer el subsector de los espectáculos públicos en el país. Para esto se busca mejorar los recursos y reducir las cargas como trámites, procedimientos, costos. En resumen, pretende: disminuir la carga tributaria, facilitar la producción reduciendo los requisitos y fortalecer las competencias del Estado para el control de las sociedades de gestión colectiva de derechos de autor. En respuesta a lo anterior, la mencionada ley consagra diversas medidas de fomento, fortalecimiento y formalización de los espectáculos de las artes escénicas (representaciones en vivo de música, danza, teatro, circo, magia y sus prácticas derivadas).

Para efectos de la aplicación de la Ley, se define en el artículo 3: que, por "artes escénicas" se entienden los espectáculos públicos de las artes escénicas, las representaciones en vivo de expresiones artísticas en teatro, danza, música, circo, magia y todas sus posibles prácticas derivadas (Ley 1493 de 2011).

La ley no contempla beneficios para otros espectáculos como corridas de todos, eventos deportivos, desfiles o ferias de modas, ferias artesanales, reinados, proyecciones cinematográficas, circos con animales, carreras de caballos, peleas de callos, espectáculos con fines religiosos, políticos, sociales o económicos. A este beneficio tienen acceso tanto las entidades sin ánimo de lucro, como instituciones públicas y empresas privadas con ánimo de lucro que estén registradas como productores de espectáculos públicos antes el Ministerio de Cultura; adicional a esto, deben presentar declaración parafiscal. Para el año 2014 se encontraban inscritos 600 proveedores entre pequeños y grandes empresarios (Ministerio de Cultura, 2014). 
De acuerdo con el artículo 5 de la Ley, uno de los beneficios será la disminución en la retención en la fuente del 33\% al 8\% para artistas no residentes en el país; este impuesto debe ser retenido por el productor o pagador de la actividad artística. Estas personas no están obligadas a pagar declaración de renta, siempre y cuando se les haya hecho la retención mencionada. De acuerdo con el artículo 6, se elimina el IVA para las artes escénicas y servicios conexos (sonido, luces, tarimas); adicional a esto se les eliminará el impuesto del 10\% correspondiente a juegos de azar y otro $10 \%$ con destino al deporte. Se espera que esto ayude a reducir los costos de boletería y abrir el acceso. Otro de los impuestos eliminados es el impuesto a los pobres, autorizado mediante el Acuerdo 399 de 2009.

Como un incentivo más para estar al día en el pago de impuestos, los productores que hayan pagados sus impuestos durante el 2011 o a más tardar el 26 de marzo de 2012, se declararán al día con todas sus obligaciones tributarias a la fecha.

Adicional a lo anterior, se genera una contribución parafiscal única (que reemplaza todos los impuestos anteriores) del 10\% sobre la boletería que estará destinada al sector cultural en artes escénicas del correspondiente municipio o distrito en el cual se realice el espectáculo. Se utilizará para la construcción, adecuación, mejoramiento y dotación de los escenarios destinados a la realización de espectáculos públicos de las artes escénicas (Decreto 1240, 2013).

El recaudo del 10\% sobre el valor de la boletería cuyo valor individual sea igual o superior a tres UVT (corresponde a \$78 147 en 2012) lo hará el Ministerio de Cultura a través de una cuenta especial. De igual manera, el Ministerio de Cultura girará los recursos de la contribución parafiscal a la Secretaría de Hacienda Municipal o Distrital donde se haya producido el espectáculo, en el mes inmediatamente siguiente a la fecha del recaudo. Para efectos del recaudo se contará con una Ventanilla Única, un espacio, físico o virtual, a nivel municipal o distrital, donde el empresario o cualquier entidad pública que quiera realizar un espectáculo podrá diligenciar todo lo relacionado con su solicitud en un plazo no mayor a 20 días. De acuerdo con la Ley 1493 cada una de las capitales departamentales deberá crear esta ventanilla.

De otra parte, el artículo 4 indica que las inversiones que se realicen en infraestructura de proyectos para escenarios habilitados o en infraestructura de escenarios habilitados existentes, destinados específicamente a la realización de espectáculos públicos de las artes escénicas serán deducibles del impuesto sobre la renta en un $100 \%$. Este cambio, en particular, solo pudo aplicarse para las inversiones que se realizaron a partir del 2012, pues es un cambio sustantivo a las normas del impuesto de renta (cuyo periodo inicia en enero 1 y termina en diciembre 31) y no se podía aplicar en el mismo año en que salió la Ley (artículo 338 de la Constitución).

Por otro lado, los trámites se reducen. Antes se debían cumplir 24 requisitos, ahora solo serán cuatro en los escenarios habilitados. Para espacios no habilitados son siete los requisitos establecidos. Para esto, la Ley 1493 establece como escenarios habilitados: aquellos "lugares en los que de manera habitual se pueden realizar 
espectáculos públicos y que cumplen con las condiciones de infraestructura y seguridad necesarias para obtener la habilitación de escenario permanente por parte de las autoridades locales correspondientes. Hacen parte de estos escenarios los teatros, salas de conciertos y en general las salas de espectáculos que se dedican a este fin"; cabe aclarar que aun en estos espacios, cada espectáculo requiere de permisos (Ley 1493, artículo 3). Los no habilitados son escenarios convencionales que no han obtenido el permiso bianual de la autoridad competente o escenarios no convencionales como edificaciones deportivas $u$ otros espacios usados por los productores de espectáculos públicos, quienes deben registrar y acreditar los siete requisitos previstos en la ley.

Para facilitar el proceso, la ley recurre a la figura del Código Contencioso Administrativo denominada 'silencio administrativo positivo', para garantizar que la persona que radica su solicitud tenga una respuesta rápida. Dicha figura establece que cuando un ciudadano solicita algo a la administración pública y esta no responde dentro del término legal establecido se entiende que el permiso solicitado ha sido concedido o autorizado (Noticias Universia, 2012).

En cuanto a los derechos de autor, la Ley 1493 incluye disposiciones relativas al cumplimiento del derecho de autor y a la determinación del ejercicio de las competencias de inspección, vigilancia y control de la Dirección Nacional de Derecho de Autor sobre las sociedades de gestión colectiva de derechos de autor y derechos conexos y entidades recaudadoras. De esta manera, se busca asegurar que los derechos de autor le lleguen a quien le corresponde: a los autores y compositores (Noticias OEI, 2012).

Por último, es importante resaltar que esta Ley le ordena a las autoridades municipales y distritales facilitar la realización y producción de los espectáculos públicas de las artes escénicas, poniendo a disposición espacios como parques, escenarios deportivos y estadios, entre otros (Secretaria de Cultura, Recreación y Deporte, 2012).

Ahora bien, la pregunta por el impacto que ha tenido la Ley de Espectáculos Públicos no tiene una respuesta "muy científica", en términos de mediciones. Hasta la fecha, dado el poco tiempo que tiene de implementada la ley, no se han hecho estudios estadísticos que permitan tener unas cifras reales. No obstante, a partir de recientes espectáculos de gran formato que se han presentado en el país, puede inferirse que la ley ha traído resultados muy positivos para el sector cultural y para el público en general.

En el 2012 se presentaron Madonna en Medellín y Paul McCartney en Bogotá, en el 2013 se presentó el Circo del Sol en Bogotá y la cantante Beyonce en Medellín. Los 4 han sido espectáculos de gran formato, que sin la ley de espectáculos públicos hubieran sido casi imposibles de realizar, de una parte por la tramitología y los altos costos de impuestos que debían pagar los artistas y de otra parte, porque para cubrir 
todos los impuestos, la boletería se hubiera tenido que vender a altísimos precios. Adicional a esto, estos espectáculos dejaron un recaudo importante para la ciudad, a través del impuesto único del 10\% sobre la boletería.

Del concierto de Madonna se estimó que por concepto de impuestos al espectáculo fueron recaudos tres mil millones de pesos, equivalentes al 10\% de las ochenta mil boletas que fueron vendidas por la organización. Los impuestos por estos dos conciertos de Madona, suman más que todos los impuestos recibidos este año por la alcaldía por todos los espectáculos que se han realizado en la ciudad. Estos sin contar los ingresos por hoteles, alimentación, trasporte, entre otros, de los cerca de treinta y dos mil turistas que visitaron a la ciudad para ver el espectáculo.

Por su parte, Bogotá había recaudado en septiembre de 2012, 2791 millones de pesos por concepto de contribución parafiscal, que grava el 10\% de la boletería o derechos de asistencia expedida. El concierto de Paul McCartney, por ejemplo, recaudó por sí solo la suma de 943 millones de pesos por contribución parafiscal.

De igual manera, en otros municipios del país se han venido recaudando estos dineros, con cifras menos significativas que en Medellín y Bogotá, y con una implementación más lenta de la Ley. Será interesante más adelante, analizar el impacto que tuvo en la ciudad de Cali la Bienal Internacional de Danza que contó con la participación de nueve compañías extranjeras.

Sin duda, esta ley pasa a ser una herramienta de gran utilidad para el sector cultural que bien puede ser aprovechada para su desarrollo y la formación de públicos; para traer al país grandes espectáculos de talla internacional y para promover así mismo los espectáculos nacionales. Hay que reconocer que el Ministerio de Cultura ha hecho una importante labor de socialización en diferentes municipios; no obstante, se hace necesario una mayor sensibilización para alcanzar una verdadera apropiación de la Ley que permita hablar de un impacto realmente considerable a nivel nacional. La implementación y la apropiación de la ley dejan ver (nuevamente) que si bien es cierto que Colombia es un país con una gran diversidad cultural, la cultura, especialmente en términos de industria, sigue estando centralizada en las grandes ciudades.

\section{Conclusiones}

Con el cambio de paradigma sobre la comprensión de la cultura, y a partir de esto, los cambios en las políticas culturales que tienen lugar en los ochenta, se introducen programas para el desarrollo de la dimensión económica del sector. Comenzamos a hablar de emprendimiento e industrias culturales, de estrategias para fortalecer el sector y posicionar los diferentes subsectores. Los productores, artistas y gestores culturales se convierten en emprendedores, desarrollan formas de asociación propias. Los gobiernos se interesan por medir el impacto que tiene la cultura en la economía y los resultados demuestran que el fortalecimiento del sector puede tener 
implicaciones muy positivas, tanto en la economía como en la construcción social de las sociedades. La UNESCO habla de un crecimiento del sector de 300\% entre 1980 y 1998.

En este orden de ideas, Colombia comienza a generar estrategias para el desarrollo del emprendimiento y las industrias culturales. Al principio se trata un poco de ideas sueltas, programas creados por algunas instituciones públicas e iniciativas del sector privado, como los fondos de financiación y los programas de formación para emprendedores, que se intentan orientar hacia la cultura. Al comienzo, el sector es poco regulado y no existen políticas para la formalización. Es en 1997 mediante la Ley 347, Ley General de Cultura, que se crea el Ministerio de Cultura y este puede entenderse como un gran primer paso para empezar a formalizar el sector y gestionar las herramientas para su desarrollo. En la primera década del 2000, el Ministerio de Cultura empieza a gestionar y liderar los procesos para sancionar las leyes de fomento a las industrias culturales y una serie de herramientas que hoy conforman un ecosistema para estas.

No obstante, hay que decir que anterior al Ministerio, ya se había creado y sancionado en el país la Ley 98 de 1993, Ley del Libro, que si bien es cierto que no se diseña dentro de un contexto de fomento a las industrias culturales, ni es este uno de sus principales objetos, con los años esta se vuelve una herramienta de fomento y gestión para el sector editorial. En este sentido, esta ley que hoy cumple 20 años, nos permite hacer un balance de los impactos que ha tenido y a la vez nos muestra cómo estas herramientas se vuelven un tanto obsoletas frente a los desafíos del presente y los grandes cambios que ha traído el desarrollo de las llamadas nuevas tecnologías. El sector cultural es sumamente cambiante y esto debe ser comprendido desde una legislación flexible y abierta a las modificaciones.

En el caso del sector editorial y de los libros, hoy en día se presenta un fenómeno de multiplicación de nichos de consumo y de productores, realizadores, creadores, consumidores y lectores; en el sector editorial esto se ve reflejado en una serie de editoriales y librerías independientes que han venido surgiendo y respondiendo a las demandas de unos lectores completamente diferentes a los de hace 20 años (Vargas, 2014). Se trata de lectores que antes que un libro buscan una experiencia, por eso prefieren libros más elaborados, y un buen librero a un simple vendedor. La Ley del Libro está en mora de conocer a los nuevos editores y lectores, de acogerse a las dinámicas globales y comprender los desafíos que presenta la era digital. De acuerdo con la última encuesta de consumo cultural (DANE, 2009), en Colombia las personas leen 1,9 libros al año; no obstante, esta cifra corresponde a libros impresos. De acuerdo con Jesús Martín Barbero,

hay una ausencia de un mapa de conexiones claves que permitan analizar entrelazadamente lo que sucede en el ámbito de los modos de leer y los contenidos de lectura en el soporte papel y en los soportes digitales. Lo que en alguna forma está exigiendo a la investigación estadística de lo cultural una afinación en la formulación de preguntas capaces de captar dimensiones cualitativas en las entrelineas de lo cuantitativo (2009). 
En ese sentido, habría que replantear las encuestas de consumo cultural que le están preguntando a nuevos consumidores, cuestiones del pasado.

El libro está pasando por una transición tecnológica y el editor debe adecuarse. Para Enrique González la industria editorial no está en extinción por cuenta de la tecnología y el libro electrónico, sino en acomodación. "El reto del editor es mantenerse en contacto con la comunidad lectora sin importar en qué medio lea. Lo importante es tener lectores", dice. Para él, la complicación es que se está en una transición tecnológica del libro en el mundo, como cuando surgió la imprenta. 'Hay escritores y hay lectores. Lo que varía es el medio, y ahí a las editoriales les toca ser creativas. Los libros deben darles valor agregado a los lectores' (Portafolio en Cámara Colombiana del Libro, 2011).

Posteriormente en el 2003 se sanciona la Ley 814, conocida como la Ley del Cine. Podría decirse que ha sido la ley mejor apropiada y con mayor impacto en un sector. Esta ley, como todas ha tenido sus detractores y sus adeptos; sin embargo, hay que reconocer, pese a las críticas y especialmente a las discusiones que se dieron en ese entonces sobre el papel que jugó Cine Colombia en la creación de la ley, que esta ha traído grandes beneficios para el desarrollo del sector y que ha permitido, especialmente, pensar el cine como industria (enrodaje). Si bien es cierto que aún nos falta mucho camino por recorrer, nuestro cine ha crecido en los últimos diez años a pasos agigantados; de rodar con grandes dificultades tres películas al año, pasamos a rodar 23; los espectadores para el cine nacional y extranjero han aumentado; los estímulos que han llegado a noventa y cinco mil millones de pesos han permitido el desarrollo de proyectos arriesgados, independientes, competitivos en espacios internacionales. El Fondo para el Desarrollo Cinematográfico, también creado mediante esta ley, se ha convertido en una importantísima herramienta para el manejo de los recursos y por tanto del crecimiento del sector. El cine ha sabido madurar como un sector de alguna manera auto sostenible, al hacer que parte de los recursos que genera retornen y se reinviertan; además como un sector que se piensa y desde sus diferentes actores.

Con la nueva ley, Ley 1556 de 2012, se presentan nuevos desafíos y oportunidades; se busca con esta herramienta que el país se vuelva un espacio para el rodaje de películas internacionales. Esta, como todas las leyes tiene su lado positivo y sus riesgos; como dice Pedro Adrián Zuluaga, reconocido periodista experto en cine, podemos convertirnos en "el paisaje" y esto en realidad no supondría un mayor desarrollo para la industria, en cambio sí dinero, pero esto no es suficiente. El reto está en saber aprovechar la llegada de productores internacionales para desarrollar un sector más competitivo, con mayor nivel, pero a la vez para desarrollar propuestas propias y hacer que ese cine nacional que viene creciendo se fortalezca con sello propio. También será una gran oportunidad para la formación de públicos, pues si bien es verdad que hoy en día van a cine muchas más personas que antes, nuestra asistencia sigue siendo muy baja, especialmente frente al cine nacional. 
Por otra parte, frente a la Ley de Espectáculos Públicos, Ley 1493 de 2011, hay que decir primero que esta fue una importante batalla que dio el Ministerio de Cultura, y que ofrece un panorama alentador para los productores de artes escénicas nacionales y extranjeros, pues de una parte reduce los costos de producción lo que se traduce en una reducción en los precios de la boletería, por tanto, se esperaría una mayor acogida por parte del público; y además, facilita los trámites para la realización de los eventos, permitiendo que productores y artistas recorran un camino mucho más transitable. Ahora, también hay que decir que esta ley es bastante nueva y que por tanto es difícil medir su impacto, pero además no ha alcanzado el nivel de apropiación deseado; esto, por supuesto, se tomará unos años. Adicional a esto, hay que reconocer que nuestro ecosistema para el desarrollo de las industrias culturales sigue estando muy centralizado, por tanto, los impactos que pueden llegar a tener estas leyes se evidencian en las ciudades principales, donde se cuenta con un músculo institucional que facilita su apropiación.

En términos generales podemos decir que estas leyes son herramientas fundamentales para formalizar y fortalecer los sectores, pero para que esto ocurra lo principal es la apropiación de los actores del sector de dichas herramientas y, para esto, es necesario extender los tentáculos del ecosistema de las industrias culturales a las regiones. Allí es donde reside uno de los mayores retos.

\section{Referencias}

Cámara Colombiana del Libro (s.f.). Recuperado de http://www.camlibro.com.co/ index.php?option=com_content \&view $=$ article $\&$ id=98:la-gran-amenaza-de-loslibros-es-la-falta-de-lectores\&catid=1:general-

DANE. (2013). Comunicado de prensa. Encuesta de consumo cultural. Bogotá. Recuperado de http://www.dane.gov.co/files/investigaciones/eccultulral/ cp_ecc_2012.pdf

Departamento Nacional de Planeación (2007). Conpes 3462 de 2007.

Enrodaje.net. Colombia 10 años de la Ley del Cine 814. Recuperado de http://enrodaje. net/10-anos-de-la-ley-de-cine-814/

Martín-Barbero, J. (2009). La investigación del consumo cultural en Colombia. Bogotá: El Tiempo. Recuperado de http://www.eltiempo.com/archivo/documento/ CMS-5050511

Ministerio de Cultura. (2009). Impacto económico del sector cinematográfico. Bogotá.

Ministerio de Cultura. (2014). Colombia cuenta con una nueva ley del cine para producciones internacionales. Proimágenes Colombia. Comisión Fílmica. Recuperado de http://www.locationcolombia.com/oldsite_2014//secciones/bole tin/noticia.php?tipo $=$ noticia\&id $=160 \&$ lang $=$ es 
Noticias Universia. (2012). Preguntas freucentes sobre la Ley 1493 del 26 de diciembre de 2011. Recuperado de http://noticias.universia.net.co/en-portada/ noticia/2012/01/09/903404/preguntas-frecuentes-ley-1493-26-diciembre-2011. html

Noticias OEI. (2012). Beneficios de la Ley de Espectáculos Públicos de las Artes Escénicas. Recuperado de http://www.oei.es/noticias/spip.php?article10986\&deb ut_5ultimasOEI=110

Restrepo, C. (2013). La estrategia de las editoriales alternativas para acaparar mercado. Recuperado de http://www.eltiempo.com/archivo/documento/CMS13154063

Revista Cromos. (2013). Editoriales Independientes: seductoras y caristmáticas. Recuperado de http://www.cromos.com.co/cultura/articulo-146120-editorialesindependientes-seductoras-y-carismaticas

Secretaría de Cultura, Recreacion y Deporte. (2012). Beneficios de la Ley 1493 para los productores de espectáculos públicos de las artes escénicas. Recuperado de http://www.culturarecreacionydeporte.gov.co/node/2434

Vargas, L. (2014). Especial Independientes: Los editores. Revista Arcadia. Recuperado el 14 de enero de 2015 de http://www.revistaarcadia.com/impresa/ especial/articulo/especial-independientes-editores/30756

\section{Leyes citadas}

Decreto 1240 de 2013. Ministerio de Cultura. Recuperado de http://www. culturarecreacionydeporte.gov.co/sites/default/files/decreto_1240_de_14_de junio_de_2013.pdf

Ley de Espectáculos Públicos. Ley 1493 del 26 de diciembre de 2011. Recuperado de http://wsp.presidencia.gov.co/Normativa/Leyes/Documents/ley149326122011.pdf

Ley del Cine. Ley 814 de 2003. Recuperado de http://www.alcaldiabogota.gov.co/ sisjur/normas/Norma1.jsp? $\mathrm{i}=8796$

Ley del Cine. Ley 1556 de 2012. Recuperado de http://www.cancilleria.gov.co/sites/ default/files/tramites_servicios/visas/archivos/ley155609072012.pdf

Ley del Libro. Ley 98 de 1993. Recuperado de http://www.alcaldiabogota.gov.co/ sisjur/normas/Norma1.jsp? $\mathrm{i}=27901$

Ley General de Cultura. Ley 397 de 1997. Recuperado de http://www.bi bliotecanacional.gov.co/rnbp/sites/default/files/attach/page/ley_397_de_1997.pdf 